\section{El Dr. Hideyo Noguchi en Yucatán.}

Dr. Pedro Cámara-Milán*

\section{RESUMEN.}

Nació el Doctor Hideyo Noguchi en la Ciudad de Wakamatsu el 24 de Noviembre de 1876. En Tokio, cursó sus estudios en la Universidad Imperial y en 1898 se graduó de Doctor en Medicina. Bajo la tutela del profesor Kitasato, ocupó el puesto de asistente a su Cátedra del Instituto para el Estudio de Enfermedades Infecciosas. Poco más tarde fue oficial de cuarentena en Yokohama y profesor de Patología general en el Colegio Dental de Tokio. En 1900 viajó a los Estados Unidos y se incorporó a la Universidad de Pensilvania, llegando a ser Médico asistente en la Escuela de Medicina y en el Instituto Carnegie de Washington. Ahí consiguió aislar en el veneno de varias especies de víboras americanas substancias tóxicas (hemolisinas, aglutininas, neurotoxinas y enzimas proteolíticas), lográndose con esto la aplicación de sueros específicos en la intoxicación ofídica. En 1903, en Dinamarca realiza sus estudios de Biología y Bacteriología, graduándose en el Instituto de Seroterapia del Estado de Copenhague. En 1904 es invitado por el Doctor Simón Flexner, Jefe de los laboratorios del Instituto Rokefeller de New York, a colaborar con él, siendo desde entonces sucesivamente asistente, socio, miembro asociado y miembro titular. En este Instituto hizo su conocida modificación a la reacción de Wasserman. En 1912 descubrió en el cerebro de un enfermo muerto por parálisis general el treponema Palidum de la Sífilis, confirmando la teoría etiológica de aquella forma de trastornos cerebrales.

Desde 1918 Noguchi se dedicó con al estudio de la fiebre amarilla y en 1920 llegó a Mérida, enviado por el Instituto Rockefeller para realizar estudios sobre esta temática y tocó a los laboratorios del Hospital O'Horán recibir en su recinto a tan ilustre sabio. La escuela de Medicina de Mérida, lo designó Doctor en Medicina y Cirugía Honoris Causa, la noche del 17 de Enero de 1920. Después de varias semanas de trabajo, su

*Trabajo póstumo publicado originalmente en la Revista de la Universidad de Yucatán, Mayo-Junio 1961, p. 11-17.

Discurso pronunciado en la ceremonia de develamiento de la estatua del Dr. Noguchi efectuada el 25 de junio de 1961 , en el Hospital "Dr. Agustín O'Horán" de la ciudad de Mérida, Yucatán. Se reproduce en conmemoración del $25^{\circ}$ Aniversario del Centro de Investigaciones "Dr. Hideyo Noguchi” de la Universidad Autónoma de Yucatán.

Solicitud de sobretiros: Revista Biomédica, Centro de Investigaciones Regionales "Dr. Hideyo Noguchi", Universidad Autónoma de Yucatán, Ave. Itzáes No. 490 x 59, C.P. 97000, Mérida, Yucatán, México. 


\section{P Cámara-Milán.}

estancia en Mérida, Yucatán, carecía de interés para él a causa de que la epidemia tocaba a su fin. Por lo que el Doctor Noguchi partió pronto al Instituto Rockefeller y posteriormente fue al Africa Occidental, a la Costa de Oro, en donde se había desarrollado una epidemia de fiebre amarilla. En Mayo de 1928 el Doctor Noguchi falleció de fiebre amarilla a los 51 años de edad.

(Rev Biomed 2000; 11:207-212)

Palabras clave: Historia de la Medicina, Hideyo Noguchi, fiebre amarilla.

\section{SUMMARY.}

\section{Dr. Hideyo Noguchi in Yucatan.}

Dr. Hideyo Noguchi was born in the city of Wakamatsu, Japan on November 24, 1876. He studied medicine at the Imperial University in Tokyo and graduated in 1898. Under the guidance of Profesor Kitasato, he occupied the post of assistant Professor at the Institute of Infectious Diseases. Later he was in charge of quarentine in Yokohama and the professor of general pathology at the Tokyo Dental School. In 1900, he travelled to the United States of America and joined the University of Pensylvania, and became assistant Doctor at the School of Medicine and at the Carnegie Institute in Washington, where he isolated toxic substances (haemolisine, aglutinine, neurotoxins and proteolytic enzymes) from the poison of several species of america snakes, thereby achieving the application of specific sera in cases of ophidian poisoning. In 1903, he carried out studies of Biology and Bacteriology and graduated from the Institute of Serotherapy of the State of Copenhagen in Denmark. In 1904, Doctor Simon Flexner, Chief of the Laboratories of the Rockefeller Institute in New York, invited him to join him, where he advanced from assistant to member, to associated member to titled member of this Institute. While he was there, he made his well-known modification to the reaction of Wasserman. In 1912, he discovered the treponema
Palidum of Syphilis in the brain of a dead patient who had died from general paralysis, thereby confirming the etiological theory of that form of brain disease.

From 1918, Dr. Noguchi dedicated himself to the study of yellow fever and in 1920, the Rockefeller Institute sent Dr. Noguchi to the Laboratories of the Hospital O'Horan, Merida, Yucatan to study this disease. The School of Medicine in Merida, were honoured to receive such a great doctor in this city and they paid tribute to him by designating him Doctor in Medicine and surgery Honoris Causa, the night of January 17, 1920. After several weeks of intense work, he lost interest in staying in Merida, Yucatan since the epidemic was nearing its end, and doctor Noguchi left for the Rockefeller Institute. Later, he went to the gold coast, Western Africa, where an epidemic of yellow fever had broken out. In May 1928, just before leaving for New York, he became ill and a few days later, Dr. Hideyo Noguchi died of yellow fever at the age of 51.

(Rev Biomed 2000; 11:207-212)

Key words: History of medicine, yellow fever, Hideyo Noguchi.

Nunca en la Historia de la Facultad de Medicina de Mérida y en la del Hospital O'Horán se había celebrado un acto de tanta significación y trascendencia para la Historia de la Medicina en Yucatán como, el que estamos celebrando en este momento: la solemne ceremonia de la entrega de la estatua del ilustre y sabio Doctor Japonés Hideyo Noguchi. Esta fue donada por la Universidad de Tamagawa, al Hospital O’Horán, en cuyos laboratorios el ilustre sabio realizó trabajos de investigación sobre la fiebre amarilla.

El Doctor Noguchi, vuelve a Mérida y a este Hospital, después de 40 años, pero esta vez en espíritu; su paso por este Hospital dejó una estela luminosa que todavía subsiste.

Es tan conocido por todos los que ejercen la 


\section{El Dr. Hideyo Noguchi en Yucatán.}

Medicina, aún en los más apartados lugares del mundo, el nombre del Doctor Noguchi, que no solamente los hombres de Ciencia estaban enterados de la marcha constante y progresiva de sus investigaciones, sino también las personas ajenas a toda cuestión científica, eran informadas por la prensa diaria, de los descubrimientos en beneficio de la humanidad del Doctor Noguchi.

Nació el Doctor Noguchi en la Ciudad de Wakamatsu el 24 de Noviembre de 1876; allí pasó su niñez y su adolescencia rodeado de aquel paisaje encantador del bello país del sol naciente, nombre bien aplicado al Japón, porque nada hay más bello que la aurora.

Muy joven fue a Tokio, habiendo cursado sus estudios en la Universidad Imperial en donde alcanzó grandes triunfos como estudiante. En 1898 se graduó de Doctor en Medicina.

$\mathrm{Su}$ amor al trabajo y su claro talento, fueron desde luego descubiertos por el ilustre profesor Kitasato, quien puso todo su empeño en que el joven Médico ocupara el honroso puesto de asistente a su Cátedra del Instituto para el Estudio de Enfermedades Infecciosas, en donde demostró su aptitud y gran afición para las investigaciones de laboratorio. Poco más tarde fue oficial de cuarentena en Yokohama y profesor de Patología general en el Colegio Dental de Tokio.

En 1900 hace su primer viaje a los Estados Unidos, incorporándose como Médico en la Universidad de Pensilvania, llegando a ser Médico asistente en la Escuela de Medicina y en el Instituto Carnegie de Washington.

Los estudios de Calmette sobre la ponzoña de las víboras y los sueros antiponzoñosos, excitaron su ambición para los descubrimientos beneficiosos a la humanidad y en sus pacientes y arduos trabajos consiguió aislar en el veneno de varias especies de víboras americanas, substancias tóxicas como 1as hemolisinas, las aglutininas, las neurotoxinas y las proteolíticas, lográndose con esto el perfeccionamiento en la fabricación de los sueros antiponzoñosos, la dosis y la aplicación de sueros específicos en la intoxicación ofídica.
En 1903 llega a Dinamarca a proseguir sus estudios de Biología y Bacteriología, graduándose en el Instituto de Seroterapia del Estado de Copenhague, dejando en aquel lugar testimonio de sus grandes aptitudes y conocimientos como investigador.

Vuelve a los Estados Unidos en 1904 y es entonces invitado por el eminente investigador Doctor Simón Flexner Jefe de los laboratorios del Instituto Rokefeller de New York a colaborar con él en los trabajos de bacteriología del mencionado instituto, siendo desde entonces sucesivamente asistente, socio, miembro asociado y miembro titular, distinción ésta última que sólo llegan a merecer los grandes hombres en la Ciencia Médica como Flexner, Noguchi y otros cuyos nombres salieron del recinto de los laboratorios para transponer las fronteras de la nación e invadir y asombrar al mundo científico con sus trabajos y descubrimientos.

Cuando su estancia en el Instituto Rockefeller por su talento y su ansia de investigar, encontró oportunidades para hacerse célebre, allí hizo su conocida modificación a la reacción de Wasserman.

En 1912 descubrió en el cerebro de un enfermo muerto por parálisis general el treponema Palidum de la Sífilis, dando así una confirmación a la teoría etiológica de aquella forma frecuente de trastornos cerebrales que se observaba después de muchos años en enfermos que habían contraído 1a sífilis.

En 1918 Noguchi se dedica con vehemencia y asiduidad al estudio de la fiebre amarilla, esta terrible enfermedad que desde tiempos muy remotos había esolado con extensas epidemias y gran mortalidad a varias regiones del mundo: Asia, Africa, Europa, pero sobre todo a la América Latina, el Sur de 1os Estados Unidos y la Isla de Cuba. Así se pasó mucho tiempo, no conociéndose de la enfermedad más que la sintomatología y la gran mortalidad que producía.

El primer paso hacia la profilaxis fue dado por el genial investigador y gran observador 


\section{P Cámara-Milán.}

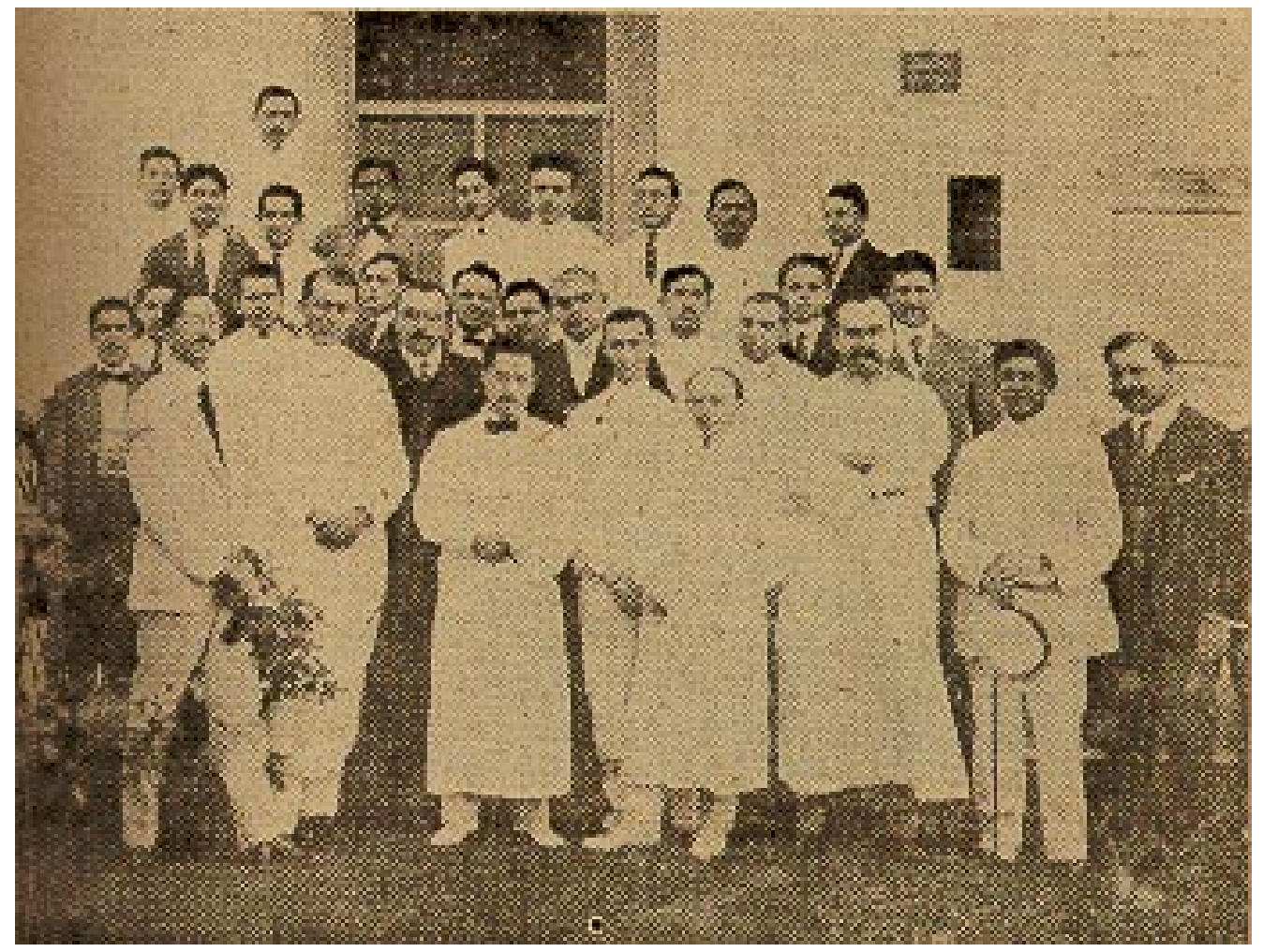

Figura 1.- Cerca del pórtico de entrada del Hospital O’Horán, a raíz de una brillante conferencia del Dr. Noguchi en los laboratorios de dicho establecimiento, se tomó esta fotografía, en la que aparecen de izquierda a derecha. los médicos siguientes: Primera fila: Carlos Casares Pérez. Efraín Gutiérrez Rivas, Hideyo Noguchi, Mario Villamil M., Israel J. Kliger (Ayudante del Dr. Noguchi), Abelardo Lara Negrón, Luis Cáceres Novelo y Antonio Aguilar.- Segunda fila: Tiburcio Martínez Campos. Ernesto Alfaro Alomía, José C. Cabañas, Manuel B. Trens, Francisco Colomé Trujillo, Rafael Pinto Manzanilla, Pedro I. Pérez Piña, Pedro Francisco Rivas, Lorenzo Méndez Miranda, José Catarino Rendón. José D. Evia y Mauro Buenfil.- Tercera fila: Gonzalo Hemández Fajardo, Fernando Aguilar Solís. Juan Helguera F., estudiante Tomás Alvarado, Nicolás Castellanos, Luis Fernández, Saturnino Guzmán Duarte, Felipe Escalante, José Jesús Moguel y Felipe Machado Ontiveros.

Médico Cubano Carlos Finlay.

El Doctor Miguel Bustamante erudito maestro, dice en su interesante $y$ bella obra "La fiebre amarilla en México": En junio de 1881 el Doctor Carlos Finlay inició sus estudios experimentales en la Habana, sobre la transmisión de la fiebre amarilla por medio del mosquito $y \mathrm{el}$ 15 de agosto leyó en la Academia de Ciencias Médicas de la Habana su trabajo titulado "El mosquito hipotéticamente considerado agente transmisor de la fiebre amarilla", en el cual sentó las bases de la profilaxis de la fiebre amarilla urbana, transmitida por el Aedes Aegypti conocido antiguamente por el Culex Fasciatus, "Estegomía faciata", y añade el Doctor Bustamante: "El genio de Finlay merece la admiración y el homenaje de todo el mundo civilizado".

Descubierto el agente transmisor faltaba por descubrir el agente causal del mal; grandes y expertos investigadores se habían dedicado con gran empeño a esto, sin obtener después de arduos estudios y horas interminables de trabajo, más que el fracaso. Los distinguidos y ameritados Médicos Cubanos Lebredo y Guiteras estuvieron en Mérida con el mismo fin, pero siempre con el mismo resultado, negativo.

Los médicos que trabajaban en el Hospital O’Horán en esa época y otros fuera de él, habían estudiado cuidadosamente toda 1a sintomatología de la enfermedad, sus primeras manifestaciones

\section{Revista Biomédica}




\section{El Dr. Hideyo Noguchi en Yucatán.}

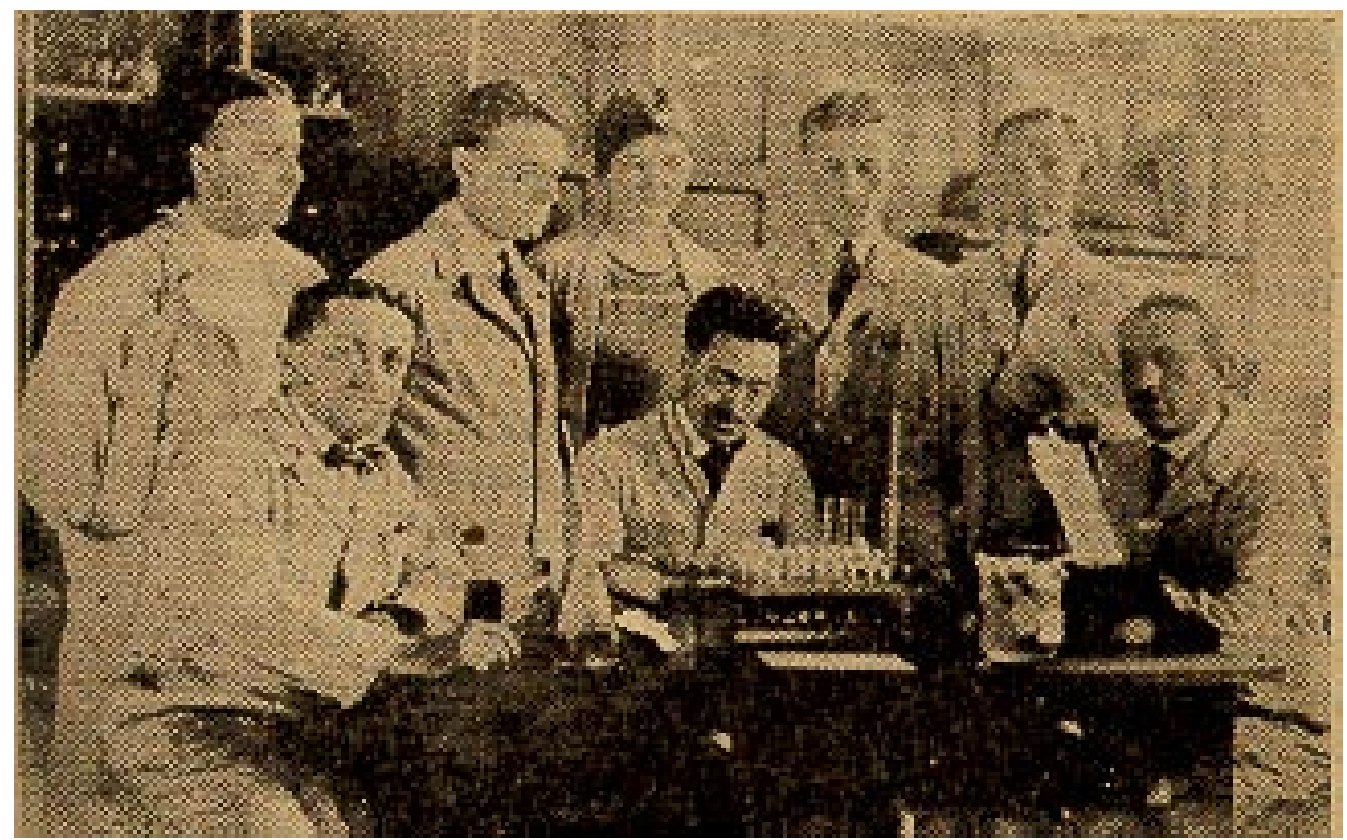

Figura 2.- Gráfica tomada en el Instituto Rockefeller de Nueva York en el año de 1922. De izquierda a derecha aparecen los médicos siguientes: segunda fila: Dieterick H. Dieterick, J. Muller, Ellis B. Tilden, (Secretaria del Dr. Noguchi), B. Rogers y Mario Villamil M.- Primera fila: Diego Hernández Fajardo, Hideyo Noguchi y Alfredo iglesias, de Veracruz.

clínicas, su evolución y las lesiones anatomopatológicas que producía en los diferentes órganos, pero faltaba para profundizar el estudio un laboratorio.

Fue en el año de 1906, por iniciativa de Don Olegario Molina, entonces Gobernador de muy gratos recuerdos para Yucatán, en que llegó el sabio doctor danés Haral Seidelin a fundar el Laboratorio de este Hospital, que fue dotado con todos los elementos más modernos conocidos en aquel tiempo, destinado no solamente para los análisis clínicos de rutina de los enfermos del Hospital, sino también para investigaciones y fue en aquel recinto sagrado de la ciencia en donde se hizo por primera vez en la república, siguiendo la técnica francesa, la reacción de Wasserman, aún no conocida en la capital más que por mera literatura y dada a conocer con la técnica detallada en la tesis de Doctorado del Doctor Efraín Gutiérrez Rivas.

Intensamente se 1aboró también bajo la dirección del Doctor Seidelín sobre la fiebre amarilla que en aquella época la epidemia era grande y la mortalidad mucha. Los Doctores Diego Hernández Fajardo, Hircano Ayuso O' Horibe y
Efraín Gutiérrez y Mario Villamil eran colaboradores incansables del Doctor Seidelin; se trabajaba día y noche, las autopsias de cadáveres de fiebre amarilla eran muchas y el material procedente de ellas que había que estudiar era abundante; cantidades de preparaciones microscópicas de sangre y de tejidos había que examinar. El objetivo era descubrir el agente invisible que producía el mal y para esto las horas de trabajo para el Doctor Seidelin y sus colaboradores eran cortas y así transcurrió el tiempo sin obtener como otros grandes investigadores más que el fracaso, pero sin perder el coraje para continuar sus labores y llegar a descubrirlo.

En 1910 el Doctor Seidelin renunció; su renuncia produjo una gran pena y desconcierto entre los Médicos del Hospital, pues todos comprendían que era una gran pérdida para el progreso de la ciencia médica en Yucatán.

Después de haber estado en varios centros científicos de Europa entre ellos para no citar otros muchos, la Escuela de Medicina Tropical de 


\section{P Cámara-Milán.}

Liverpool, se le envió al Congo Belga, en donde la fiebre amarilla era endémica, a continuar sus investigaciones sobre esta enfermedad; allá después de una larga estancia contrajo una corta enfermedad sin esperanza de curación. Fue trasladado a Amberes, Bélgica, en donde falleció en abril de 1932. El mundo perdió a un eminente hombre de ciencia.

En 1920 llega a Mérida el sabio y tenaz investigador Japonés Doctor Hideyo Noguchi, enviado por el Instituto Rockefeller para continuar los estudios sobre la fiebre amarilla, que aún presentaba el irresoluto problema de descubrir el agente que producía el terrible mal que había causado numerosas víctimas en Mérida.

Fue una gran honra para los laboratorios del Hospital O’Horán recibir en su recinto a tan ilustre sabio conocido por sus trabajos de investigación, en todas partes del mundo científico; descubrir el agente que produce la fiebre amarilla era el fin que se proponía para librar a la humanidad de esta terrible enfermedad que producía una mortalidad muy elevada.

Desde luego comenzó sus labores; la gran epidemia que había asolado a Mérida y parte del Estado en esa época, ya estaba declinando. Los casos eran pocos y había dificultad en conseguir material fresco para su estudio.

Sin embargo a pesar de esto el Doctor Noguchi, como hombre hecho de la madera de los sabios, no perdió el interés ni el entusiasmo en buscar el ser invisible que había causado la muerte a millares de personas en varias partes del mundo y trabajaba en e1 laboratorio de este Hospital como acostumbraba hacerlo en los grandes laboratorios.

La presencia en Mérida de tan eminente personalidad científica médica, no podía pasar inadvertida para los médicos de Yucatán que ya ha tiempo conocían al Doctor Noguchi por sus trabajos publicados en revistas Médicas Extranjeras y mucho menos a la escuela de Medicina de Mérida. En esta época era Director el distinguido maestro Doctor Don Francisco Colomé y Trujillo que consideró un deber en la escuela honrar a tan ilustre sabio tributándole un homenaje en que se le nombrara Doctor en Medicina y Cirugía Honoris Causa. Fueron nombrados los doctores Efraín Gutiérrez Rivas y Abelardo Lara para que le entregaran al Doctor Noguchi la comunicación con el acuerdo de la escuela y para que se sirvieran acompañarlo a1 local de la misma la noche del 17 de Enero de 1920, fecha en que se celebró tan solemne ceremonia con asistencia de casi todos los médicos del Estado.

La estancia del Doctor Noguchi en Mérida después de varias semanas de trabajo intenso, ya carecía de interés para él a causa de que la epidemia tocaba a su fin. Los casos eran poco frecuentes, el material para estudio era escaso o faltaba. El Doctor Noguchi necesitaba el tiempo para emplearlo en otros trabajos aplazados; parte pronto para su laboratorio del Instituto Rockefeller a informar de sus labores en Mérida.

Algún tiempo más tarde partió, siempre enviado por el Instituto Rockefeller, para el Africa Occidental a la Costa de Oro en donde se había desarrollado una epidemia de fiebre amarilla y era necesaria su presencia. Allá tardó bastante tiempo trabajando intensamente a pesar del gran calor. En Mayo de 1928 precisamente antes de embarcarse para New York, tuvo que guardar cama por encontrarse bastante enfermo. Nueve días después el mundo científico se conmovió ante la noticia de la muerte del Doctor Noguchi. Falleció de fiebre amarilla a los 51 años de edad. La ciencia y el mundo habían perdido a un gran hombre, al Doctor Hideyo Noguchi.

\section{Revista Biomédica}

